\title{
Effects of handling and context preexposure on the immediate shock deficit
}

\author{
JESUS LANDEIRA-FERNANDEZ, MICHAEL S. FANSELOW, \\ JOSEPH P. DECOLA, and JEANSOK J. KIM \\ University of California, Los Angeles, California
}

\begin{abstract}
The immediate shock deficit refers to the failure of a shock to become associated with contextual stimuli when the shock is presented simultaneously with the rat's placement in a context. The basic procedure consists of a presentation of the shock as soon as the animal is placed in an observation chamber. Handling of the animal, which immediately precedes the shock, and the novelty of the chamber in which the immediate shock is delivered are potential variables that might be responsible for this associative deficit. In Experiment 1, handling reduced context conditioning but was not responsible for the immediate shock deficit. Experiment 2 revealed that the novelty of the chamber was not a significant factor. These results discount the possibility that handling and the novelty of the chamber are responsible for the deficit produced by the immediate shock. It is suggested that immediate shock could be employed as a control procedure for the study of context conditioning.
\end{abstract}

When a rat is exposed to a chamber and shortly after that a single shock is delivered, the rat freezes. This freezing response, which is characterized by an immobile crouching posture, is also observed when the animal is returned to the same chamber $24 \mathrm{~h}$ after the presentation of the shock. It has been shown that freezing is a conditional response that is differentially controlled by the contextual stimuli in the place in which the animal has received the shock (see, e.g., Fanselow, 1980). This contextual conditioning, however, can be precluded if the shock is presented simultaneously with the rat's placement in the chamber (Blanchard, Fukunaga, \& Blanchard, 1976; Fanselow, 1986, 1990). Typically, no freezing response occurs with an immediate shock. This failure of the animal to associate the contextual stimuli with the shock has been termed the immediate shock deficit.

The standard immediate shock procedure consists of the presentation of the aversive electric shock simultaneously with the placement of the animal in the experimental chamber. Control animals receive a delayed shock, which occurs 2 or $3 \mathrm{~min}$ after placement. The time difference at the beginning of the session between the immediate and delay conditions, the handling that immediately precedes the shock presentation, and the novelty of the ex-

National Institute of Mental Health Grant MH39786 to M.S.F. supported this research. This paper was prepared while M.S.F. was a fellow at the Center for Advanced Study in the Behavioral Sciences. Fellowship support was provided by John D. and Catherine T. MacArthur Foundation Grant 8900078 . J. L.-F. was supported by a fellowship from Conselho Nacional de Desenvolvimento Cientifico of the Ministry of Science, Brazil. We thank Kathy Chin for editorial assistance. J.J.K. is now at the University of Southern California. Address reprint requests to M. S. Fanselow, Department of Psychology, University of California, Los Angeles, CA 90024-1563 (e-mail: fanselow@psych.sscnet.ucla.edu).

-Accepted by previous editor, Vincent M. LoLordo perimental chamber in which the immediate shock is delivered are potential variables that can interfere with conditioning or its expression. These three variables could be responsible for the deficit in association formation. For example, the handling cues that precede the presentation of the immediate shock could overshadow the contextual stimuli and thus disrupt context conditioning. In the case of the novelty of the experimental chamber, the contextual stimuli could elicit different responses, such as exploration, which could compete with the conditional response. In the present experiments, these variables were manipulated and their effects on the immediate shock deficit were investigated.

\section{EXPERIMENT 1}

One unique feature of the immediate shock procedure is that handling immediately precedes the presentation of the shock. It is possible that this handling can act as a conditional stimulus that overshadows conditioning of contextual stimuli. Several procedures have been used to reduce the impact of the handling variable. For example, Blanchard et al. (1976) briefly handled the delayed group before the shock presentation so that handling was always present before shock in the immediate and the delay shock conditions. One problem with this procedure is that animals in the delay shock group were handled twice (when they were placed in the chamber and immediately before the shock presentation), whereas animals in the immediate shock group were handled just once. Fanselow (1986, 1990) did not handle the delayed animals before shock, so that all animals were handled only once during the experiment. The influence of handling was reduced by adapting the animals to handling 5 days before the beginning of the experiment. The problem with this procedure is that only the immediate group had handling contiguous with shock. 
In addition, there was no assurance that the handling adaptation procedure prior to the experiment was effective in reducing the potential influence of handling on context conditioning. The Fanselow $(1986,1990)$ and Blanchard et al. (1976) designs coped differently with the handling variable, and each study contained a different confound.

In these earlier studies, immediate shock animals received the shock upon placement into the chamber, whereas the delay shock animals were placed in the chamber sometime before the shock. Therefore, one could argue that the immediate shock deficit is due to the lack of exposure to a context different from the home cage prior to shock or merely due to differences in time elapsed between home cage and shock.

In the present experiment, these issues were addressed by equating handling and exposing the immediate shock animals to a different context before the presentation of the immediate shock. Therefore, time and amount of handling in the immediate and the delay conditions were identical. It was also the purpose of this experiment to investigate whether handling immediately before presentation would affect context conditioning. This issue was examined by comparing the amount of conditioning between animals that received a delayed shock when they were handled and those that were not handled immediately before the shock. If handling immediately prior to shock produces the immediate shock deficit, then delayed shock rats handled immediately before shock should behave as do immediate shock rats.

\section{Method}

Subjects. Sixty male Long-Evans rats between 70 and 90 days old and weighing $350-450 \mathrm{~g}$ served as subjects. They were bred in the UCLA Psychology Department colony. The animals, individually housed in hanging stainless steel cages, had food and water ad lib. All rats were experimentally naive, and each animal was briefly handled every day for 5 days before the start of the experiment. The experiment was conducted during the light portion of a 12:12-h light:dark cycle.

Apparatus. Two sets of different types of chambers were used in this experiment. The first set (Context A) consisted of four identical chambers measuring $28 \times 21 \times 22.5 \mathrm{~cm}$ (Lafayette Instruments), each of which was placed inside a sound-and light-attenuating chest with no front panel. The chambers were made of transparent acrylic, except for the lateral walls that were made of stainless steel. Ventilation fans attached to the interior of each chest supplied a background noise of $78 \mathrm{~dB}$ (A). An ammonium hydroxide solution (5\%) was used to clean the chambers before and after running each subject. Room lights were on continuously.

The second set (Context $B$ ) consisted of two chambers with a trapezoidal form. These chambers were $11 \mathrm{~cm}$ high. Each chamber's floor was $10 \mathrm{~cm}$ long and $21 \mathrm{~cm}$ deep; the ceiling was $20 \mathrm{~cm}$ long and $21 \mathrm{~cm}$ deep. Each chamber was placed inside the light- and sound-attenuating chest. Ventilation fans were turned off, and $1 \mathrm{ml}$ of vanilla extract was placed inside the chest. A sodium hydroxide solution (1\%) was used to clean the boxes before and after each conditioning session. Floors in both sets of chambers (Context A and Context B) were composed of stainless steel rods ( $4 \mathrm{~mm}$ in diameter) spaced $1.5 \mathrm{~cm}$ center to center. Individual shock generators and scramblers (Lafayette Instruments) were wired to each chamber. A hand switch and a timer allowed the experimenter to present a $1-\mathrm{sec}, 2-\mathrm{mA}$ electric shock.
Procedure. The 60 animals were randomly assigned to five equally sized groups. Table 1 summarizes the training procedures for the five groups. The group names were designed to describe the procedures. The first letter signifies the first context in which the animal was placed, and the second letter corresponds to the second context (the second context could be the same as, or different from, the first). The symbol separating these two letters indicates whether animals were handled. An " $X$ " represents handling and a "-" signifies no handling. Group A-A was exposed to Context $A$, in which a shock was presented 3 min later. Animals from this and all other groups were removed from the chamber and returned to their home cages $20 \mathrm{sec}$ after the shock. This procedure has been used extensively in our laboratory to produce context conditioning. The second Group, $\mathrm{A} \times \mathrm{A}$, was included to determine whether handling had some deleterious effect on context conditioning. This was achieved by briefly handling the animals before the shock presentation. These animals underwent the same procedure as did the first group, with the exception that they were handled just before shock presentation. Handling consisted of removing the animals from the chamber and immediately placing them back into the designated chamber. The issues of amount of handling and the exposure to a novel context prior to the delivery of the immediate shock were addressed by inclusion of Group B $\times$ A. Animals in this group were exposed to Context B for $3 \mathrm{~min}$ and then removed from this context and placed in Context $\mathrm{A}$, in which an immediate shock was delivered. Again, $20 \mathrm{sec}$ after the shock presentation, animals were returned to their home cages. The immediate shock was delivered as soon as the chamber's door was closed. Animals in the Group $\times A$ served as a control for the exposure treatment. They had the same procedure as did the $\mathrm{B} \times \mathrm{A}$ group with the exception that they were not exposed to Context $B$. Animals in this group received the immediate shock in Context A. Finally, the fifth group, $B \times B$, was included to assess whether conditioning to Context A was specific. Animals were conditioned in Context B and then tested in Context A. They were exposed to Context B for 3 min and promptly placed back into Context $B$, in which an immediate shock was presented. On the next day, all the animals were tested in Context $\mathrm{A}$ for $4 \mathrm{~min}$. The experiment was conducted in a series of two replications. The first replication consisted of four groups with 8 animals in each group. The fifth group, along with the remainder of the other four groups, was run in the second replication. Freezing, defined as the absence of any visible movement of the body and vibrissae except for the movement necessary for respiration, was scored according to a time-sampling procedure. Animals were tested in sets of four. Freezing was scored at intervals of $8 \mathrm{sec}$ by an experimenter who was unaware of the experimental conditions.

\section{Results and Discussion}

There were no reliable differences between replications, so the data were pooled across replications. Nonparametric statistics were employed to analyze the data in all the experiments reported here. This was done because previous experiments demonstrated a complete absence of freez-

Table 1

Summary of the Training Procedures of Each of the Five Different Groups of Experiment 1

\begin{tabular}{lccc}
$\begin{array}{c}\text { Group } \\
\text { Name }\end{array}$ & $\begin{array}{c}\text { Context } \\
\text { Exposure }\end{array}$ & $\begin{array}{c}\text { Handling Prior } \\
\text { to Shock }\end{array}$ & $\begin{array}{c}\text { Immediate } \\
\text { Shock }\end{array}$ \\
\hline A-A & A & no & A \\
A $\times$ A & A & yes & A \\
B $\times$ A & B & yes & A \\
$\times \mathrm{A}$ & home cage & yes & A \\
B $\times$ B & B & yes & B \\
\hline
\end{tabular}


ing when animals were exposed to immediate shock but not when they were exposed to delayed shock (Fanselow, 1986, 1990). This lack of variance in the immediate shock group resulted in heterogeneity of within-group variance across conditions. Therefore, the Kruskal-Wallis test was used to determine overall differences among groups, followed by the Mann-Whitney $U$ test for pairwise comparisons.

Figure 1 presents the median percentage of time spent freezing in all five groups. A clear immediate shock deficit can be seen in Groups $\mathrm{B} \times \mathrm{A}$ and $\times \mathrm{A}$ as opposed to the two delayed shock Groups, $\mathrm{A} \times \mathrm{A}$ and $\mathrm{A}-\mathrm{A}$. The virtual absence of freezing in the two immediate shock groups was indistinguishable from the behavior of Group $B \times B$, which was not shocked in Context $A$. An effect of handling was evident in the reduced freezing seen in Group $A \times A$ as opposed to Group $\mathrm{A}-\mathrm{A}$. The only procedural difference between these two groups was the brief handling that Group $A \times A$ received immediately before shock.

Group $B \times A$ was exposed to Context $B$ before training but not testing. However, the lack of freezing in this group cannot be attributed to generalization decrement, because Group $\times$ A showed a similar lack of freezing even though it was treated similarly before training and testing.

Statistical analysis confirmed this general pattern. An overall difference among groups was found $[H(4)=36.4$, $p<.01]$. Pairwise comparisons revealed that Group A-A, which was not handled before the presentation of the shock, differed from all the other groups. The difference between Group A-A and Group A $\times$ A was reliable $[U(12,12)$ $=8, p<.01]$. This result indicates that handling the animals just before the presentation of the shock decreases context conditioning. Nevertheless, this reduction in context conditioning induced by handling does not constitute the sole mechanism for the immediate shock deficit. Group AXA, which was handled immediately before the shock presentation, showed reliably more conditioning than did Group $B \times A$, which received an immediate shock

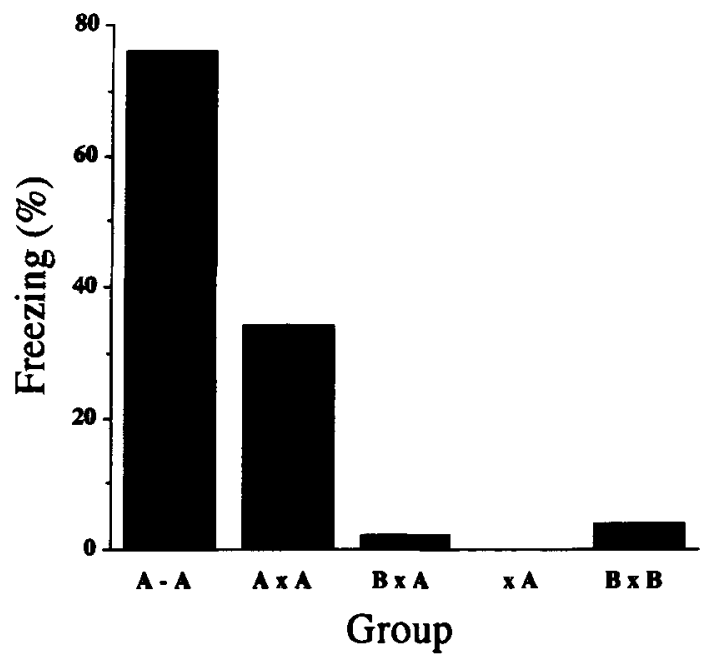

Figure 1. Median percent freezing observed in Experiment 1. Freezing was measured in Context $A$. after being exposed to a different context $[U(12,12)=$ $31.5, p<.02]$. Although handling the animals prior to shock presentation attenuated context conditioning, this deficiency cannot account for the immediate shock deficit.

Conditioning observed in Group A X A was context specific. This conclusion is supported by a reliable difference between this group and Group $B \times B$, which had the same procedure as did Group $\mathrm{A} \times \mathrm{A}$, but in a different context $[U(12,12)=8, p<.01]$. In addition, exposing the animals to a different context before the delivery of the immediate shock did not alleviate the immediate shock deficit since the difference between the $\mathrm{B} \times \mathrm{A}$ and $\times \mathrm{A}$ groups did not approach statistical reliability $[U(12,12)=63]$. These two findings support the notion that it is the difference in amount of context conditioning between the $A \times A$ and $\mathrm{B} \times \mathrm{A}$ groups that characterizes the immediate shock deficit. Thus, an immediate shock deficit was observed with an identical amount and temporal distribution of handling.

\section{EXPERIMENT 2}

Experiment 1 showed that handling immediately before the delivery of the shock is not exclusively responsible for the immediate shock deficit. In addition, exposing the immediate shock animals to a different context before shock did not alleviate the immediate shock deficit, even though it equated the total amount of handling and exposure time to a novel context prior to the shock for Groups $A \times A$ and $\mathrm{B} \times \mathrm{A}$. However, animals that received the immediate shock had less total exposure to the shock context than did animals that received delayed shock. It is possible that during the test, the immediate shock animals could have been engaging in an exploratory response elicited by the novelty of the chamber. Therefore, one could argue that the immediate shock deficit reflects a performance deficit resulting from response competition arising from such exploration. That is, since the chamber is more novel in the immediate shock than in the delayed shock rats, noveltyinduced exploration masks freezing in the immediate shock rats.

Fanselow (1986) showed that preexposing the immediate shock animals to the experimental chamber at least $15 \mathrm{~min}$ before the delivery of the immediate shock did not alleviate the immediate shock deficit. This result suggests that the immediate shock deficit is not a performance failure. However, the Fanselow (1986) experiment did not incorporate the handling control procedure used in the first experiment. Since in Experiment 1 conditioning was partially disrupted by handling, it is plausible that an interaction between handling and response competition might have been responsible for the immediate shock deficit. In Experiment 2, we tested this alternative by employing a procedure in which the amount of handling and exposure to a novel context were matched between the immediate and delay groups.

\section{Method}

Subjects and Apparatus. Forty-eight male Long-Evans rats with the same characteristics as those of the rats in the previous experi- 
ments were trained and tested in the same apparatus. The only difference was that Context $B$ was cleaned with a $1 \%$ acetic acid solution instead of sodium hydroxide and no vanilla scent was employed.

Procedure. The experiment was performed in two separate replications. The 48 animals were equally and randomly divided into four groups. The treatment of Groups $\mathrm{A} \times \mathrm{A}$ and $\mathrm{B} \times \mathrm{A}$ was identical to that in Experiment 1 . The purpose of these two groups was to demonstrate the basic immediate shock deficit. To test whether this deficit was due to the novelty of the context where the immediate shock was presented, the animals in the third group were exposed to Context A $15 \mathrm{~min}$ before they received the immediate shock. The 15 -min interval was based on a previous study (Fanselow, 1986). Group A/B $\times A$ was exposed to Context $A$ for $3 \mathrm{~min}$ and then returned to their home cages. Fifteen minutes later, these animals were exposed to Context $B$ for $3 \mathrm{~min}$ and then removed from this chamber and placed in Context $A$, where the immediate shock was delivered. Twenty seconds later, the animals were returned to their home cages. A fourth group served as a control group for the preexposure manipulation. Animals in Group B/A $\times A$ had the same procedure as did Group $\mathrm{A} / \mathrm{B} \times \mathrm{A}$, with the difference that they were first exposed to Context $B$ and then to Context $A$. Therefore, animals in these two groups received the same amount of exposure not only to Context $A$ where the shock was presented but also to Context $B$. The next day, all animals were reexposed to Context $\mathrm{A}$ for $4 \mathrm{~min}$, and freezing was scored by an experimenter who was unaware of the experimental conditions.

\section{Results and Discussion}

Figure 2 presents the median percentage of time spent freezing in the four groups. An immediate shock deficit was observed that was independent of context novelty. Groups $A / B \times A$ and $B \times A$ froze substantially less than did Groups $B / A \times A$ and $A \times A$. A Kruskal-Wallis analysis revealed an overall difference among groups $[H(3)=12.61$, $p<.01]$. As suggested by the figure, preexposure to the context where immediate shock was delivered had no reliable effect; there was no reliable difference between the group that was preexposed to the context where the immediate shock occurred $(\mathrm{A} / \mathrm{B} \times \mathrm{A})$ and the group that did not have preexposure $(B \times A)[U(12,12)=55.5]$. Moreover, a reliable difference between Group $\mathrm{A} / \mathrm{B} \times \mathrm{A}$, which

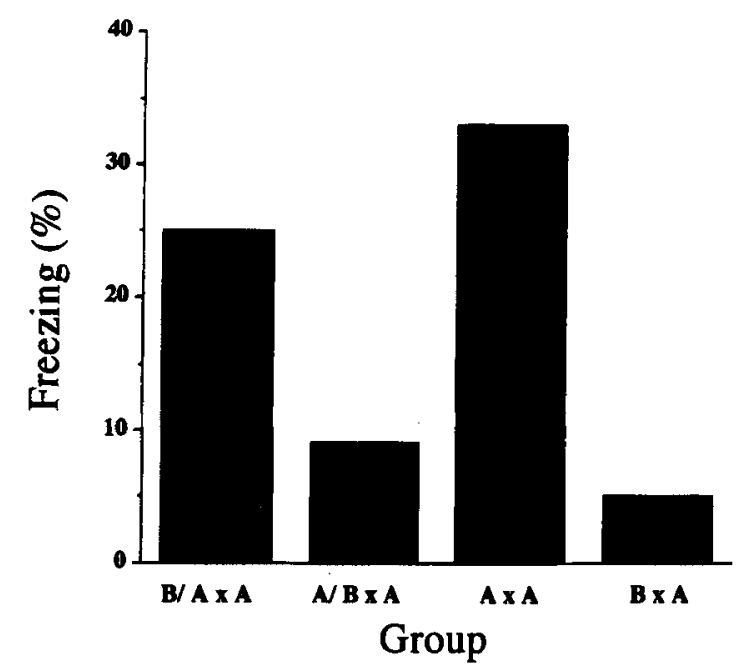

Figure 2. Median percent of freezing observed in Experiment 2 . Freezing was measured in Context $A$, in which shock was presented. was preexposed to the context where immediate shock was delivered, and its control Group $\mathrm{B} / \mathrm{A} \times \mathrm{A}$, was found $[U(12,12)=37, p<.05]$. These results accord with Fanselow (1986) and indicate that the novelty of the context is not responsible for the immediate shock deficit. Finally, Groups $\mathrm{A} \times \mathrm{A}$ and $\mathrm{B} \times \mathrm{A}$ differed reliably $[U(12,12)$ $=37, p<.05]$. This result replicates the finding from the previous experiment. Again, the immediate shock deficit was evident when amount of handling and exposure to a distinct environment other than the home cage was matched across groups.

\section{GENERAL DISCUSSION}

The immediate shock deficit refers to the finding that animals do not exhibit context conditioning when the shock is presented immediately upon placement into the experimental chamber. The present experiments indicate that the handling that immediately precedes the delivery of the shock and the novelty of the shock context do not cause the immediate shock deficit.

In Experiment 1, although handling the animals immediately before shock attenuated context conditioning, this deleterious effect of handling could not account for the immediate shock deficit. An immediate shock deficit was observed when handling was equated in the groups exposed to the immediate and delayed shock. Exposing the animals to a different chamber before the presentation of the immediate shock did not affect the context conditioning deficit. In sum, the immediate shock deficit was still present when the total amount of handling and exposure to a distinct environment were matched between the delay and immediate shock groups.

A competing response account of the immediate shock deficit based on exploratory responses elicited by the novelty of the immediate shock chamber was not supported by the results of Experiment 2. Exposing the animals to the experimental chamber $15 \mathrm{~min}$ before the presentation of the immediate shock did not alleviate the immediate shock deficit. This result is in agreement with Fanselow (1986) and replicates those results with the present handling procedure. Thus, handling and context novelty do not interact to attenuate the deficit. The immediate shock deficit is still observed when the effect of handling is equated in preexposed animals.

The present results do not suggest what types of processes are involved in the immediate shock deficit. It has been proposed that the immediate shock deficit reflects an associative deficit between the shock and the context where the shock is immediately presented (Fanselow, 1986, 1990). Recent work suggests that this associative deficit arises because shock can disrupt the memorial representation of the context and can directly suppress conditioning (Fanselow, DeCola, \& Young, 1993). US preexposure, in a different context, acts to habituate this disruptive effect of immediate shock on association formation (Fanselow et al., 1993, Experiment 4). Whatever the underlying process for the immediate shock deficit, it is clear from the present experiments that the associative deficit is not a product of 
handling or performance factors. Therefore, we suggest that the immediate shock procedure can be a useful sensitization and pseudoconditioning control for the study of context conditioning. In this way, animals can be exposed to the unconditional stimulus in the context where conditioning takes place but association formation is prevented.

\section{REFERENCES}

Blanchard, R. J., Fukunaga, K. K., \& Blanchard, D. C. (1976). Environmental control of defensive reactions to footshock. Bulletin of the Psychonomic Society, 8, 129-130.

FANSELOW, M. S. (1980). Conditioned and unconditioned components of post-shock freezing. Pavlovian Journal of Biological Sciences, 15, 177-182.
FANSELOW, M. S. (1986). Associative vs topographical accounts of the immediate shock freezing deficit in rats: Implication for the response selection rules governing species specific defensive reactions. Learning \& Motivation, 17, 16-39.

FANSELOW, M. S. (1990). Factors governing one-trial contextual condjtioning. Animal Learning \& Behavior, 18, 264-270

Fanselow, M. S., DeCola, J. P., \& YounG, S. L. (1993). Mechanisms responsible for reduced context conditioning with massed unsignaled unconditional stimuli. Journal of Experimental Psychology: Animal Behavior Processes, 17, 121-137.

(Manuscript received February 22, 1994; revision accepted for publication September 15, 1994.) 